\title{
Aproximación a la multiliteracidad en el nivel 1 de ESPA: elaboración de un diaporama sobre derechos humanos a partir de la novela En un lugar del Atlántico.
}

Recibido: septiembre 2011

\author{
Eduardo CABORNERO \\ CEPA de Entrevías, Madrid \\ Isabel GARCÍA PAREJO \\ Universidad Complutense de Madrid \\ igarcia@edu.ucm.es
}

Aceptado: marzo 2012

\section{RESUMEN}

Este artículo describe una secuencia didáctica desarrollada por profesores y alumnos de secundaria de un centro de educación de personas adultas de Madrid. El objetivo de la secuencia es el diseño y elaboración de un diaporama que toma como base el tema de los derechos humanos. El fin último de este diaporama es ser expuesto ante un público para que, a partir de su proyección, se pueda establecer un diálogo entre los participantes sobre la realidad presentada a través del mismo. En la medida en que el diaporama exige la lectura y la escritura en diferentes códigos y que su diseño y desarrollo cuentan con la colaboración de los profesores de todas las áreas del conocimiento, la experiencia didáctica resulta de gran interés para el desarrollo de diferentes habilidades comunicativas.

Palabras clave: multiliteracidad, educación de personas adultas, secuencia didáctica, diaporama

\section{Approach to Secondary Adult Basic Education multiliteracy: making a human rights slideshow from the novel Le Ventre de l'Atlantique}

\begin{abstract}
This article describes a teaching sequence developed by adult basic education teachers and students in Madrid. The aim was to design and develop a slideshow based on the theme of the Human rights. The ultimate goal was to exhibit the slideshow so that a dialogue could be established among those present based on the reality described in it. We suggest that, insofar as the slideshow not only involves reading and writing in different codes but also requires the collaboration of teachers from all areas of knowledge, this teaching experience is of much interest for the development of diverse communicative skills.
\end{abstract}

Key words: multiliteracy, adult basic education, didactic sequence, slideshow 
Approche de la multilittératie au niveau 1 de ESA: élaboration d'un diaporama sur les droits humains à partir du roman En un lugar del Atlántico (Le ventre de l'Atlantique) de Fatou Diome

\section{RÉSUMÉ}

Cet article décrit une séquence didactique mise en pratique par des professeurs et des élèves de niveau secondaire d'un Centre pour Éducation de Personnes Adultes (CEPA) de Madrid. L'objectif essentiel de la séquence est d'élaborer un diaporama basé sur le thème des droits de l'homme. La finalité ultime est une projection publique du diaporama qui puisse donner lieu à un dialogue entre les participants au sujet de la réalité décrite. Dans la mesure où le diaporama requiert des codes multiples du point de vue de la lecture et l'écriture et que sa mise au point et son développement dépendent de la collaboration de professeurs ayant des connaissances dans tous les domaines, cette expérience didactique présente un grand intérêt pour le développement de diverses habiletés communicatives.

Mots clé: multilittératie, éducation de personnes adultes, séquence didactique, diaporama

SUMARIO: 1. Introducción. 2. La educación secundaria en el CEPA de Entrevías. 3. Un proyecto de escritura multimodal: diaporama sobre una novela. 3.1. La preparación del proyecto. 3.2. El desarrollo de la secuencia didáctica. 4. A modo de valoración final. Referencias bibliográficas.

"Il court, tacle, dribble, frappe, tombe, se relève et court encore. Plus vite!" "Corre, dribla, regatea, chuta, cae, se levanta y sigue corriendo. ¡Más rápido!”

Le Ventre de l'Atlantique (Fatou Diome)

\section{INTRODUCCIÓN}

Con el texto que hemos recogido al principio comienza la novela Le Ventre de l'Atlantique (En un lugar del Atlántico, en la traducción española) de Fatou Diomé, y su inicio simboliza, al menos en su primera etapa, la vida frenética de cualquier inmigrante africano en Europa. No tan frenética resulta la experiencia de producción escrita multimodal que queremos presentar a lo largo de este capítulo, pero nos sirve para describir, de alguna manera, el trabajo realizado por el grupo de nivel 1 de ESPA (Educación Secundaria para Personas Adultas) del centro de educación de personas adultas (CEPA) de Entrevías, situado en el distrito de Vallecas de Madrid.

Sin embargo, antes de describir esta experiencia, conviene contextualizar esta rama del sistema educativo, ya que suele quedar al margen de los estudios y propuestas formativas del profesorado. Sobre la Educación de Personas Adultas (EPA), la Declaración de la V Conferencia Internacional celebrada en Hamburgo en 1997 señaló que 
"Por educación de personas adultas se entiende el conjunto de procesos de aprendizaje, formal o no, gracias al cual las personas cuyo entorno social considera adultos desarrollan sus capacidades, enriquecen sus conocimientos y mejoran sus competencias técnicas o profesionales o las reorientan a fin de atender sus propias necesidades y las de la sociedad"

Existe una relación directa entre los cambios que se producen en nuestro entorno a nivel económico, social, político y cultural y aquellos que se producen en el desarrollo de la EPA en cada país. Sin embargo, como señala Tuijnman (1996), entre otros, la educación de adultos se siente como prioridad entre los gobiernos debido, principalmente, a los efectos de estos cambios demográficos y económicos. En toda Europa se constata el envejecimiento de la población, el crecimiento del grupo de personas jubiladas, de jóvenes trabajadores sin cualificación, de grupos de inmigrantes... Nos sentimos arrastrados por los cambios tecnológicos y últimamente por los económicos: ciertos trabajos exigen una cualificación técnica, y el mercado de trabajo se cierra cada vez más para aquellos que no tienen una formación y pueden ser considerados como analfabetos funcionales en la sociedad actual (cf. Raggatt et al., 1996 y Jabonero, 1995). En este contexto, la formación profesional se siente como una prioridad por parte de los gobiernos, influenciados, tanto por los cambios económicos producidos desde los años setenta, como por la actual crisis económica. Ahora bien, si por un lado la filosofía de la UNESCO parece apuntar hacia el aprendizaje adulto y global a lo largo de la vida (cf. Cabello 2002), por otro, las políticas educativas, sobre todo europeas, no parecen favorecer en los últimos años el desarrollo de esta filosofía (cf. Field 1993, Flecha 1994). Es en la reforma educativa de 1990 recogida en la LOGSE, ley que desarrolla los Decretos referentes a las enseñanzas mínimas en educación primaria y secundaria, donde la educación de personas adultas aparece por primera vez como algo independiente (LOGSE: Título III), ya que hasta entonces, debido a su carácter compensatorio, se interpretaba igual que la educación primaria. Es de destacar en ella la concepción de la educación de adultos como un proceso permanente cuyo objetivo es desarrollar "su capacidad de participación en la vida social, cultural, política y económica" (LOGSE (art.51.2)). En este sentido, tanto en la LOGSE como en el documento previo a la misma, el Libro Blanco para la Educación: cap.XII ${ }^{I}$, se reflejan muchas de las experiencias y propuestas de los movimientos sociales de los 70 que consideraron la educación de personas adultas como

${ }^{1}$ Véase al respecto el volumen 8 de la revista Diálogos (diciembre, 1996) con el tema monográfico "Diez años del Libro Blanco de Educación de Adultos". 
emancipatoria (Jansen et al. 1996:125) y como parte de una transformación social (Stock 1996:11). ${ }^{2}$

Así, En el Título Tercero, artículo 51.2., se definen los tres objetivos que debe perseguir la EPA:

(i) proporcionar y actualizar la formación básica y facilitar el acceso de los adultos a diferentes niveles educativos;

(ii) mejorar su cualificación profesional o proporcionarle una preparación para el ejercicio de otras profesiones y

(iii) mejorar su capacidad de participación en la vida social, cultural y económica.

Estos objetivos se acompañan de una metodología basada en el autoaprendizaje de los adultos en función de sus experiencias, sus necesidades e intereses, en las dos modalidades educativas, presencial o a distancia, y marcan como público prioritario aquel que tiene carencias en educación básica y capacitación profesional.

Los campos de actuación de la educación de adultos quedaron recogidos en las siguientes áreas:

- Formación orientada al trabajo

- Formación para el ejercicio de los derechos y responsabilidades cívicas

- Formación para el desarrollo personal

- Formación general de tipo compensatorio.

\footnotetext{
${ }^{2}$ En esta época, proliferaron un gran número de entidades ciudadanas que, influidas por las ideas de Freire sobre cambio social a partir de la educación, el trabajo en equipo, la reflexión comunitaria, etc., se centraron en potenciar la alfabetización, la cultura general, la animación sociocultural, la educación integral y el trabajo con mujeres. Paralelamente, el gobierno ofertaba unos programas de claro carácter compensatorio, orientados a obtener una titulación básica. Como señala Cabornero (1992), las entidades ciudadanas siguen vivas, y no sólo tratan de compensar déficits académico-administrativos, sino que surgen de las necesidades humanas del entorno y tratan de incidir sobre él. A este tipo de asociaciones habría que sumar, en la actualidad, las asociaciones creadas por colectivos específicos de inmigrantes, agrupados principalmente por el país de origen, así como las ONGs, las entidades religiosas y los sindicatos que se dedican total o parcialmente a la EPA y que, en el caso de la enseñanza del español a inmigrantes adultos, han sido pioneros en su desarrollo y organización. (Para conocer las ideas de Freire puede verse Blanco (1982), y para la evolución de la educación de adultos en España Flecha et al. (1988), así como el capítulo II de García Carrasco (coord./1997).
} 
La formación de tipo compensatorio, que vuelve a ser prioritaria para las políticas educativas actuales, se imparte mayoritariamente en centros públicos dependientes de las Comunidades Autónomas y los ayuntamientos, y se desarrolla a lo largo de seis cursos, desde el ciclo inicial (alfabetización) hasta el Graduado de Secundaria para Personas Adultas (ESPA), que es equivalente al Graduado de Secundaria oficial.

Actualmente, Ley Orgánica 2/2006, de 3 de mayo, de Educación (BOE 4 de mayo), Artículo 66.3, establece los siguientes objetivos para las personas adultas:

a) Adquirir una formación básica, ampliar y renovar sus conocimientos, habilidades y destrezas de modo permanente y facilitar el acceso a las distintas enseñanzas del sistema educativo.

b) Mejorar su cualificación profesional o adquirir una preparación para el ejercicio de otras profesiones.

c) Desarrollar sus capacidades profesionales, en los ámbitos expresivos, comunicativo, de relación interpersonal y de construcción del conocimiento.

d) Desarrollar su capacidad de participación en la vida social, cultural, política y económica y hacer efectivo su derecho a la ciudadanía democrática.

e) Desarrollar programas que corrijan los riesgos de exclusión social, especialmente de los sectores más desfavorecidos.

f) Responder adecuadamente a los desafíos que supone el envejecimiento progresivo de la población asegurando a las personas de mayor edad la oportunidad de incrementar y actualizar sus competencias.

g) Prever y resolver pacíficamente los conflictos personales, familiares y sociales. Fomentar la igualdad efectiva de derechos y oportunidades entre hombres y mujeres, así como analizar y valorar críticamente las desigualdades entre ellos.

Estos objetivos se concretan en unos ámbitos de actuación que son la Formación Básica; la Formación Ocupacional y las enseñanzas de carácter no formal. Nuestra experiencia se enmarca en los grupos de formación básica, concretamente, en el nivel 1 de educación secundaria ( $5^{\circ}$ curso de EPA).

\section{LA EDUCACIÓN SECUNDARIA EN EL CEPA DE ENTREVÍAS}

El CEPA de Entrevías se encuentra situado en el barrio de Entrevías, en el distrito del Puente de Vallecas, al sureste de Madrid. En los últimos 15 años ha visto modificada su oferta no sólo por la política educativa de la Comunidad Autónoma, sino también por los cambios demográficos sufridos en el entorno, un entorno que, si ya era multicultural por la presencia de población gitana, ahora se ha enriquecido por la llegada de otros colectivos. 
En lo que se refiere al público que asiste al CEPA, este recibe al público prioritario que marcó la LOGSE, es decir, aquel que tiene carencias en educación básica y capacitación profesional, y considera "adulto" a toda persona mayor de 18 años y menor de 65 . Independientemente tanto de la edad como de las leyes que marcan el inicio de esa etapa, algunas características comunes son que se corresponde con el periodo de vida más productivo, al ser la época de rendimiento laboral; suele conllevar la fundación de una familia y, además, es el momento del ejercicio político en que el individuo muestra autonomía plena (Quintana Cabanas y Sanz Fernández, 1997). ${ }^{3}$

A nivel general, son adultos que deben añadir a sus muchas responsabilidades una tarea nueva: el aprendizaje. Además, las experiencias personales que se reúnen en el grupo de adultos son de lo más heterogéneas (la mayoría de este grupo son trabajadores) y la psicología evolutiva del adulto influye en los procesos de aprendizaje (cf. Alonso y Gallego, 1991:27). En este sentido, habría que señalar que los adultos buscan experiencias de aprendizaje que sean útiles para manejar sucesos específicos derivados de los cambios que se van produciendo en su vida (matrimonio, despido, empleo, inmigración...), al no resultarles el aprendizaje gratificante por sí mismo. Aprenden con la esperanza de aplicar lo aprendido a algo que les reportará ventajas inmediatas. Así, el interés influye mucho en su aprendizaje, ya que si el curso no le satisface, tienden a abandonarlo. (García Llamas, 1986). Por otro lado, se observa que ciertas leyes rigen todo su proceso de aprendizaje, como por ejemplo la resistencia del adulto al cambio ${ }^{4}$, la emotividad y

${ }^{3}$ Un desarrollo más completo de las etapas de la edad adulta puede verse en González y Gisbert (1990:17-19). Hay que señalar, sin embargo, que cada cultura decide cuándo comienza la edad adulta y cuáles son los objetivos de cada etapa. Así, por ejemplo, antes de la implantación de la LOGSE, la educación obligatoria llegaba hasta los 14 años, edad en la que, en caso de no ampliar uno su formación hasta los 16 años en un centro de EGB, podía acceder al mercado laboral o bien a programas de formación profesional o de garantía social en los centros de educación de personas adultas. Actualmente, todo el recorrido se centra en una educación obligatoria hasta los 16 años, que puede ser ampliada hasta los 18, edad exigida para matricularse hoy en un CEPA. Además, entre los 18 y 25 años, en nuestra sociedad, se entiende que el objetivo prioritario sigue siendo la educación, la obtención de un título. Sin embargo, la idea de "adulto" en otras culturas se acerca más al sentido etimológico: la palabra procede del verbo latino "adolescere", que significa "crecer", y es la forma del participio pasado "adultum", es decir "el que ha terminado de crecer o de desarrollarse, el crecido" (Ludojoski, 1986, en Fernández Arenaz, 1990:11). En Entrevías, ha sido una constante la negociación de la asistencia al CEPA de adolescentes gitanas y de jóvenes que tienen como expectativa incorporarse al mundo laboral.

${ }^{4}$ Así, podemos encontrar cierta dificultad a la hora de cambiar de tema en una situación de aprendizaje. O puede ocurrir que el adulto esté acostumbrado a un tipo concreto de respuesta 
la motivación. Así, necesita sentirse arropado por el grupo, aunque le cueste moverse dentro de él. Por esto, debe prevalecer, durante el aprendizaje del adulto, un ambiente de cordialidad y de trato de igual a igual tanto en las relaciones con el formador como en las relaciones entre los propios compañeros.

La organización de los cursos de secundaria en el CEPA de Entrevías es la general establecida para la ESPA. Los centros no están obligados a desarrollar un proyecto curricular, por lo que los contenidos curriculares oficiales son recogidos por los centros en sus programaciones anuales, tal como se especifican para cada uno de los campos de conocimiento: Lengua Española e Inglés (que conforman el campo de la comunicación), Matemática, Naturaleza y Sociedad.

Los cursos de educación secundaria se corresponden con los dos últimos años de la formación básica de EPA. Los profesores habilitados para poder impartir clase en estos niveles es variado: en el nivel 1 de ESPA (el $5^{\circ}$ curso de EPA) pueden compartir curso profesores de educación primaria y secundaria, mientras que en el nivel 2 (el $6^{\circ}$ curso de EPA), sólo pueden impartir docencia los profesores de secundaria.

La experiencia que presentamos a continuación es una propuesta de trabajo conjunto en los niveles de educación secundaria, evitando la excesiva fragmentación que supone la división por áreas de conocimiento. La búsqueda de información y exposición final de un tema, que puede articularse desde cualquier área, permite el desarrollo de diferentes estrategias que inciden en la consecución de los objetivos generales de la educación de personas adultas.

\section{UN PROYECTO DE ESCRITURA MULTIMODAL: DIAPORAMA SOBRE UNA NOVELA}

Entendemos por diaporama, en nuestro contexto pedagógico, un montaje audiovisual que, utilizando como soporte las diapositivas de PowerPoint, mezcla imagen con sonido y texto escrito. ${ }^{5}$

El diseño y elaboración de un diaporama, en este contexto, es una actividad didáctica de grupo que se genera a partir de un tema, en este caso los derechos humanos, y se construye para presentar un determinado mensaje a una audiencia, en esta ocasión otros alumnos adultos del centro. El objetivo último del diaporama es ser expuesto ante un público, ya que a partir de su proyección se persigue establecer un diálogo entre los participantes para reflexionar sobre la realidad

para resolver un problema y le resulta muy difícil cambiar de sistema cuando las características del problema así lo puedan exigir (cf. González y Gisbert (1990: 27)).

${ }^{5}$ El DRAE (22a edición) define diaporama como "técnica audiovisual que consiste en la proyección simultánea de diapositivas sobre una o varias pantallas, mediante proyectores combinados para mezclas, fundidos y sincronización con el sonido". (V. Palazón (2001); y Moreno Pons (2003), entre otros). 
presentada a través del mismo. Así entendido, cualquier actividad didáctica puede utilizar como recurso el diaporama para alcanzar objetivos y contenidos de diferente naturaleza, pero como intentaremos mostrar a lo largo de estas páginas, es una herramienta muy valiosa para acceder a diferentes fuentes de información y desarrollar competencias relativas a la capacidad de observación, reflexión y análisis crítico de la realidad, así como para explorar las posibilidades de la exposición multimodal. En este sentido, el diseño de la actividad didáctica con diaporamas deberá tener en cuenta tres momentos para llevar a cabo su montaje: (i) el momento de preparación, en el que alumnos y profesores, de todas las áreas de conocimiento, se comprometen en el proyecto; (ii) el momento de elaboración y edición, en el que alumnos y profesores conocen y revisan sus conocimientos sobre el tema sobre el que quieren debatir, pero también sobre las técnicas de diseño que exige la construcción del diaporama y los tipos de textos que incluye; y (iii) el momento de expresión o puesta en común, en el que grupo y audiencia descubren el trabajo final y reflexionan conjuntamente sobre el tema planteado a través del diaporama. La evaluación conjunta sobre los aprendizajes conseguidos y sobre todo el proceso desarrollado suele cerrar la secuencia didáctica.

El proyecto de elaboración de un diaporama surge motivado por circunstancias internas a la propia dinámica del aula, esto es, la necesidad de cubrir unos contenidos curriculares. Pero, al mismo tiempo, intenta enlazar la experiencia escolar con alguno de los acontecimientos socioculturales externos a ella, en este caso, el aniversario de la Declaración Universal de los Derechos Humanos (DDHH).

\subsection{La preparación del proyecto}

Como hemos señalado, el momento de preparación supone el diseño conjunto y el compromiso de todos los profesores del nivel que forman parte de la comunidad educativa, ya que el proyecto propuesto incluye el acercamiento a formas y usos de diferentes tipos de textos y el acercamiento a un tema cuyas causas y consecuencias pueden abordarse desde múltiples perspectivas: la inmigración.

Así, uno de los aspectos que consideramos fundamental en el desarrollo de nuestra experiencia es la reunión conjunta del profesorado, coordinado, en esta ocasión, desde el campo de Sociedad. En esta reunión, se propone el proyecto y la manera de abordarlo, esto es, la elaboración de un diaporama cuyo tema de estudio sea la relación entre derechos humanos e inmigración. El hilo conductor será el libro de Fatou Diome, La aventura del Atlántico y la posibilidad de relacionar sus capítulos con artículos de la Declaración Universal de los DDHH, ya que ese curso coincide con el aniversario de la misma. El libro narra, a lo largo de catorce capítulos, la historia de un joven senegalés y de su hermana que vive en Estrasburgo. Como es habitual entre los inmigrantes, mantienen un canal de comunicación constante entre ellos a través del teléfono. Sus conversaciones suelen 
tratar de fútbol, de la vida en la isla de Niodior (Senegal), y de la vida los inmigrantes que van llegando a Francia, por lo que los temas que se plantean enlazan fácilmente con los artículos de la Declaración Universal de los Derechos Humanos.

Para facilitar la organización del trabajo se presenta una plantilla de doble entrada en la que se recogen, por un lado, los contenidos que cada área está desarrollando a lo largo del trimestre y, por otro, las posibles líneas de colaboración de cada profesor para poder avanzar hacia el montaje final y hacia la convocatoria de un debate público abierto a todos los adultos del centro (Véase cuadro número 1$)$.

Cuadro número 1: Compromiso del grupo de profesores en la tarea final

\begin{tabular}{|c|c|c|}
\hline & Lo que estoy haciendo o voy a hacer & Lo que puedo aportar desde mi campo \\
\hline $\begin{array}{l}\frac{\pi}{\pi} \\
\frac{\pi}{0} \\
0 \\
0 \\
n\end{array}$ & $\begin{array}{l}\text { Economía, Demografía y Derechos } \\
\text { Humanos }\end{array}$ & $\begin{array}{l}\text { Aniversario de la Declaración } \\
\text { Universal de Derechos Humanos } \\
\text { (DDHH) } \\
\text {. Coordinar una actividad } \\
\text { multidisciplinar que gire alrededor de } \\
\text { este tema: elaboración de un diaporama }\end{array}$ \\
\hline 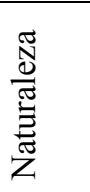 & $\begin{array}{l}\text { Energía } \\
\text { Medios de comunicación } \\
\text { (televisión, teléfono, internet,...) }\end{array}$ & $\begin{array}{l}\text { Apoyar las lecturas y añadir otras: } \\
\text { globalización, efectos de los medios de } \\
\text { comunicación }\end{array}$ \\
\hline 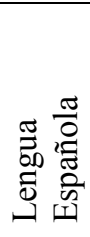 & $\begin{array}{l}\text { Textos periodísticos } \\
\text { Lenguaje publicitario }\end{array}$ & $\begin{array}{l}\text {. Apoyar las lecturas y el análisis de } \\
\text { textos e imágenes. } \\
\text {. Apoyar la escritura y la redacción de } \\
\text { crónicas de los diferentes actos que se } \\
\text { realicen. }\end{array}$ \\
\hline$\underset{\substack{\infty \\
\infty}}{\infty}$ & $\begin{array}{l}\text { Programación que incluye funciones } \\
\text { comunicativas, léxico y gramática }\end{array}$ & $\begin{array}{l}\text {. Buscar la versión en inglés y/ o } \\
\text { francés del libro. } \\
\text {. Comentar fragmentos del texto. } \\
\text {. Comentar léxico (préstamos, } \\
\text { extranjerismos) }\end{array}$ \\
\hline 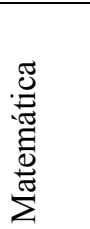 & $\begin{array}{l}\text { Programación que incluye cálculo, } \\
\text { conceptos y problemas }\end{array}$ & $\begin{array}{l}\text { Apoyar el estudio de escalas y } \\
\text { proporcionalidad para la lectura } \\
\text { estadística que pueda aparecer en } \\
\text { Sociedad o Naturaleza. }\end{array}$ \\
\hline
\end{tabular}




\begin{tabular}{|c|c|c|}
\hline 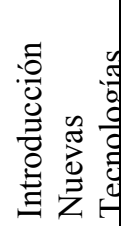 & $\begin{array}{l}\text { Programación que incluye programas } \\
\text { básicos de procesamiento de textos, } \\
\text { imágenes y acceso a la información. }\end{array}$ & $\begin{array}{l}\text { Apoyar en el diseño de diapositivas a } \\
\text { través del uso del Power Point. } \\
\text { Apoyar en la elaboración de los } \\
\text { trabajos dejando tiempos a lo largo del } \\
\text { proceso }\end{array}$ \\
\hline
\end{tabular}

Las reuniones del profesorado sirven, de igual manera, para resolver otro tipo de problemas que pueden dificultar el desarrollo de la tarea. Así, por ejemplo, se entiende que es necesario facilitar un determinado número de ejemplares del libro para la biblioteca del centro. Por otra parte, en la medida en que la elaboración del texto exige una fase de búsqueda de información, es necesario valorar las posibilidades de acceso a internet y a otras fuentes de documentación por parte del alumnado. El porcentaje de acceso a redes informáticas suele ser de un $30 \%$ entre el alumnado adulto y, aunque el centro cuenta con un aula de informática, su disponibilidad es limitada. En este sentido, es fundamental el dejar tiempos en todas las áreas para poder desarrollar el proyecto. Uno de los temores más extendidos entre el alumnado adulto es el tiempo que tendrán que dedicar al estudio, ya que este es una carga añadida a sus múltiples obligaciones. La posibilidad de trabajar todas las áreas en un proyecto común facilita la distribución de la tarea sin romper el ritmo de cada una de ellas, que es la preocupación, por su parte, del profesorado. (Véase cuadro número 2). Durante estas semanas, el contacto entre los profesores se mantiene a través del cuaderno de aula que se utiliza habitualmente, y en el que se anotan las incidencias de cada día. Además, resulta interesante abrir un fichero informático en el que recoger los diferentes materiales elaborados en cada área para poder ser utilizados en otros cursos.

Cuadro número 2 Desarrollo de actividades en el tiempo

\begin{tabular}{|c|l|l|}
\hline Semana & Desarrollo de actividades por campos de conocimiento \\
\hline $1^{\mathrm{a}}$ & Sociedad & $\begin{array}{l}\text {. Presentación del tema, animación, retos y tareas } \\
\text {. Presentación del libro En un lugar del Atlántico, primera } \\
\text { lectura }\end{array}$ \\
& Matemáticas & $\begin{array}{l}\text { Situar geográficamente los lugares que se citan } \\
\text {. Cálculo de distancias entre países } \\
\text { - Cálculo de superficies } \\
\text {. Cálculo demográfico }\end{array}$ \\
\hline $2^{\mathrm{a}}$ & Sociedad & $\begin{array}{l}\text {. Presentación de la Declaración Universal de DDHH } \\
\text {. Lectura de artículos } \\
\text {. Trabajo en grupos: elección de un artículo de la } \\
\text { Declaración-búsqueda de imágenes } \\
\text {. Análisis de características textuales I }\end{array}$ \\
\hline
\end{tabular}




\begin{tabular}{|c|c|c|}
\hline & & \\
\hline $3^{\mathrm{a}}$ & $\begin{array}{l}\text { Naturaleza } \\
\text { Comunicación } \\
\text { Nuevas } \\
\text { Tecnologías }\end{array}$ & $\begin{array}{l}\text {. Lectura de capítulos } \\
\text {. elección de un párrafo por grupo y asociación con } \\
\text { un artículo del la Declaración Universal de DDHH } \\
\text {. primer guión de la diapositiva } \\
\text {. Lectura sobre los diferentes medios de comunicación } \\
\text {. Análisis de características textuales II } \\
\text {. Uso de programas de presentación de texto con imágenes }\end{array}$ \\
\hline $4^{\mathrm{a}}$ & $\begin{array}{l}\text { Nuevas } \\
\text { Tecnologías } \\
\text { Sociedad } \\
\text { Comunicación }\end{array}$ & $\begin{array}{l}\text { Edición de diapositivas } \\
\text {. Debate abierto, con ponentes externos al Centro, sobre } \\
\text { Derechos Humanos e inmigración } \\
\text {. Presentación de todos los borradores } \\
\text {. Modificaciones }\end{array}$ \\
\hline $5^{\mathrm{a}}$ & Sociedad & $\begin{array}{l}\text { Visionado previo del diaporama } \\
\text {. Preparación de la sesión abierta }\end{array}$ \\
\hline $6^{\mathrm{a}}$ & Todo el grupo & $\begin{array}{l}\text {. Presentación del diaporama en un acto abierto a todo el } \\
\text { Centro }\end{array}$ \\
\hline
\end{tabular}

\subsection{El desarrollo de la secuencia didáctica}

La secuenciación de las actividades se pueden organizar alrededor de cinco fases: (i) un momento de animación y negociación del proyecto que coincide, fundamentalmente, con la presentación del libro; (ii) un momento de búsqueda de información, trabajo en grupo y toma de decisiones; (iii) un momento de preparación y textualización que da forma al diaporama; (iv) un momento de puesta en escena colectiva que sirve para la revisión del primer borrador; y (v) el momento de la edición del diaporama definitivo que culmina con el debate y exposición públicos y la evaluación. (Véanse cuadros 3 al 7 para más detalles). ${ }^{6}$

Lo que caracteriza nuestra secuencia es que a lo largo de todo el proceso se intenta motivar a los alumnos desde el cuestionamiento de experiencias previas que

\footnotetext{
${ }^{6}$ Tomamos como referencia el modelo de Secuencia Didáctica sugerido por el Grupo Didactext (2006) recogido también en García Parejo (2011).
} 
permitan enlazar estas con el proyecto que están desarrollando, ya que en la edad adulta resultan especialmente importantes los aprendizajes que se perciban rentables en alguna medida (Cf. García parejo 2004). De igual manera, en cada fase, se procuran utilizar recursos y técnicas que favorezcan la puesta en práctica de habilidades orales y escritas de diferente naturaleza, así como el trabajo individual y en grupo.

Cuadro número 3. Primera fase

\section{Animación - negociación del tema: emigración-inmigración (campo Sociedad)}

El derecho de los seres humanos a elegir un país en el que vivir

Previos:

- ¿Qué entiendes por emigración e inmigración?

- ¿Conoces a personas cercanas que hayan emigrado?

- ¿Qué personajes famosos conoces con experiencias migratorias?

- ¿Qué derechos tienen las personas en cuanto a movilidad entre países?

- ¿Qué conoces sobre la Declaración Universal de Derechos Humanos (DDHH)?
. Lectura de noticias periodísticas relacionadas con el tema general, Cine forum, lectura de artículos de la Constitución Española

. Presentación del libro: En un lugar del Atlántico

. Lectura de capítulos

. Resúmenes a modo de crónicas periodísticas

. Cómics

. Posibles finales para la historia

. Presentación de la Declaración Universal de Derechos Humanos

. Relación con las lecturas

. Consenso sobre DDHH y lectura

. Debate sobre alcance y limitaciones de esos artículos

. Propuestas: ¿hacia dónde?

\section{Productos de esta fase:}

. Lluvia de ideas

. Resúmenes, en diferentes formatos, de diversos capítulos del libro

. Declaración consensuada de derechos humanos

. Carteles

. Textos libres 
En esta primera fase, por ejemplo, los alumnos han manifestado sus primeros intereses, sentimientos y saberes sobre el tema de los derechos humanos y sobre la migración. Han podido acceder ya a diferentes fuentes de información y a formas de comunicación multimodal. Estas experiencias quedan plasmadas en carteles donde asocian imágenes con textos, en este caso, con los artículos comentados del a Declaración Universal de Derechos Humanos (véase imagen número 1).

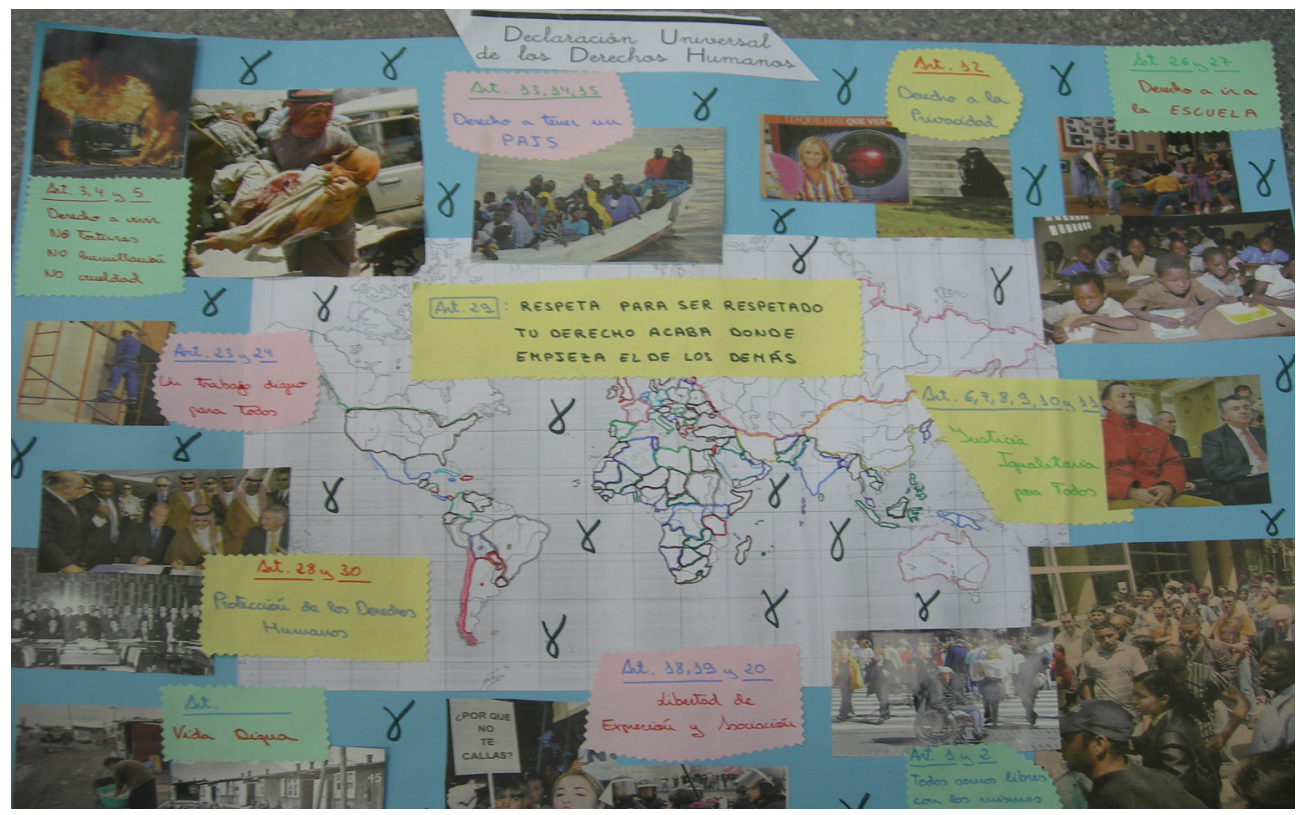

Imagen número 1: Carteles realizados a propósito del estudio sobre la Declaración Universal de los DDHH

El recorrido por los diferentes tipos textuales comienza, en la clase de Lengua, por la narración, ya que el texto base es una novela. Pero en este caso, el ejercicio de síntesis y búsqueda de ideas principales que supone resumir cada capítulo ayuda al desarrollo de estrategias fundamentales para el dominio de los textos académicos. Como se puede observar en estos ejemplos de algunos resúmenes elaborados por los alumnos, las relaciones entre oralidad y escritura ${ }^{7}$, así como la progresión temática que permita una mayor coherencia textual serán alguno de los aspectos que deberán abordarse en la fase de textualización.

\footnotetext{
${ }^{7}$ le va mal, le pillan, había cogido costumbres; y luego... cf. uso de $y_{\ldots,}$ y..., y...
} 
Moussa es un habitante del poblado senegalés y va a Francia por medio de un representante francés porque quiere jugar al fútbol y triunfar. Alli le va mal, termina regresando y miente al poblado y a N'detare, pero le pillan y luego nadie le hace caso y se ríen de él, además había cogido costumbres de los blancos.

(Manuel, alumno de ESPA. Sobre el capítulo 6)

"La hermana de Madicke les cuenta a su hermano y primo todo lo que le pasó el primer día que llegó a Francia. Había muchos emigrantes, uno de ellos fue curioso, porque era turista y su hija había nacido alli y quería poner el nombre de una señorita, estaban casi siempre discutiendo y había muchos problemas con la documentación”.

(Alicia, alumna de ESPA)

La segunda fase se centra, fundamentalmente, en la toma de decisiones y la exploración sobre el formato de edición y la exposición final, con lo que supone de estudio sobre la audiencia. Al mismo tiempo se sigue avanzando en la búsqueda de información sobre inmigración y derechos humanos con ponentes invitados y la lectura sistemática de los capítulos del libro. Como se ve en el cuadro número 4, un gran peso de esta fase recae en el estudio sobre diaporamas, imágenes y exposición multimodal, por lo que se hace imprescindible la colaboración entre profesores.

Cuadro número 4. Segunda fase

2. Negociación-búsqueda de información: tema, audiencia, tipo de texto-formato (Campos: Sociedad; Naturaleza; Comunicación; Introducción a las Nuevas Tecnologías;

Matemáticas) 
Previos:

¿Es interesante que el resultado del debate llegue a más público?

¿Cómo podría editarse la "declaración del grupo sobre derechos humanos"?

- ¿Qué técnicas y programas informáticos conoces?

Organización del diaporama:
Toma de decisiones:

. Sesión abierta para los alumnos del Centro con algún ponente invitado.

. El montaje audiovisual puede servir como introducción al debate

. Presentación sobre lenguaje visual y técnicas de proyección

. Descripción de imágenes

. Ejercicios técnicos sobre imágenes

. Se visualizan modelos

. En grupos, cada uno de ellos es encargado de diseñar una diapositiva en la que se relacione un capítulo del libro, con uno de los artículos de la Declaración Universal de DDHH.

. Se busca información en prensa, en películas, en series de televisión

. Se revisa la documentación

. Se organiza un esquema o guión

\section{Productos de esta fase:}

. Análisis de textos de diferentes naturaleza

. Lectura crítica de diferentes documentos en diferentes áreas del currículum

. Esquemas y guiones

. Toma de decisiones colectivas y trabajo en grupo

La siguiente fase es la de mayor ajetreo entre los grupos (V. imagen 2). Cada uno de ellos ha tenido que elegir un artículo de la declaración de DDHH, un párrafo de libro con el que creen que se relaciona, y ahora deben proponer una imagen para exponer la idea que quieren trasmitir. A cada grupo se le entrega un guión técnico que incluye los siguientes apartados y que, una vez completados, compondrán el primer borrador del diaporama (Véase anexo 1):

\begin{tabular}{|l|l|l|l|l|l|}
\hline Diapositiva & $\begin{array}{l}\text { Texto 1 } \\
\text { artículo } \\
\text { DDHH }\end{array}$ & $\begin{array}{l}\text { Texto 2 } \\
\text { párrafo } \\
\text { libro }\end{array}$ & $\begin{array}{l}\text { Imagen } \\
\text { posible } \\
\text { (especificar } \\
\text { técnica) }\end{array}$ & $\begin{array}{l}\text { Música } \\
\text { posible }\end{array}$ & $\begin{array}{l}\text { Tiempo de } \\
\text { exposición } \\
\text { necesario }\end{array}$ \\
\hline Número 1 & & & & & \\
\hline Número 2 & & & & & \\
\hline Número $\mathrm{n}$ & & & & & \\
\hline
\end{tabular}




\section{Cuadro número 5. Tercera fase}

\section{La elaboración del diaporama (Campos: Sociedad; Naturaleza; Comunicación; Introducción a las Nuevas Tecnologías; Matemáticas)}

\begin{tabular}{|l|c|}
\hline Previos: & $\begin{array}{c}\text {. Cada grupo realiza una diapositiva que contiene: } \\
\text {. un párrafo del capítulo del libro }\end{array}$ \\
$\begin{array}{l}\text { El guión sobre finalidad y tipo de } \\
\text { texto }\end{array}$ & $\begin{array}{c}\text {. el artículo de la Declaración de los DDHH } \\
\text {. la imagen que relaciona los dos aspectos } \\
\text {. puede ser fotografía, pintura } \\
\text { El guión sobre el contenido de la dibujo propio }\end{array}$ \\
$\begin{array}{l}\text { diapositiva } \\
\text { ¿por qué ese párrafo se } \\
\text { relaciona con ese artículo? } \\
\text { ¿qué imagen representa la idea }\end{array}$ \\
$\begin{array}{l}\text { que queréis transmitir? } \\
\text { ¿por qué? }\end{array}$ \\
$\begin{array}{l}\text { Productos de esta fase: } \\
\text { Primer borrador - guión técnico de las diapositivas } \\
\text { Trabajo en equipo consensuado }\end{array}$ \\
\hline
\end{tabular}

Imagen número 2: Un momento de la tercera fase, preparación de una diapositiva del diaporama.

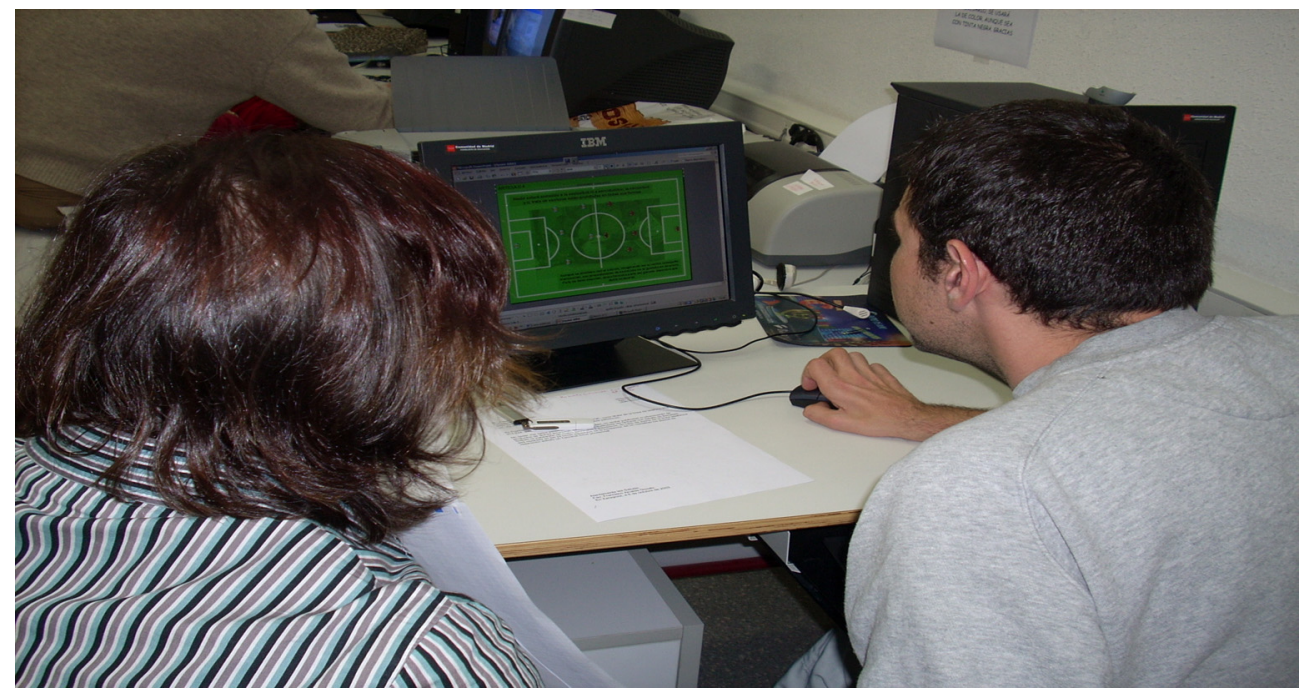


Una vez que se han reunido todas las diapositivas, el primer borrador se proyecta a todo el grupo y se revisa y evalúa conjuntamente teniendo en cuenta los objetivos propuestos. Es necesario revisar, por un lado, cómo la imagen elegida o elaborada llega a trasmitir el mensaje que se quiere asociar al artículo de la declaración de DDHH o al párrafo elegido y, por otro, si esa imagen elegida es la mejor para el público que va a estar presente en la exposición. De esta manera, todo el grupo participa en la edición definitiva y se evitan repeticiones entre las diapositivas (véase anexo 2).

Cuadro número 6. Cuarta fase

4. La revisión del primer borrador (Campos: Sociedad; Naturaleza; Comunicación; Introducción a las Nuevas Tecnologías; Matemáticas)

\section{Previos:}

El guión sobre finalidad y tipo de texto

El guión sobre el contenido de la diapositiva
. Se presenta en grupo el primer borrador de cada diapositiva . ¿se ha llegado a transmitir la idea que se pretendía? - ¿llegará al público al que va dirigido? - ¿habría que modificar algún aspecto?

. Se toman decisiones para que en el montaje final no se produzcan repeticiones

. Se diseña y elabora por grupos un cartel y un folleto para la sesión pública:

. incluye un resumen del libro; una biografía de la autora; una reseña de la Declaración Universal de los DDHH, una presentación de la tarea realizada en clase

\section{Productos de esta fase:}

. Guión final del diaporama . Cartel . Folleto de presentación _. Trabajo en equipo consensuado

Finalmente, el grupo se centra en la preparación del evento público diseñando carteles anunciadores (véase imagen 3) y panfletos de presentación. Lo más 
gratificante para todos es el momento de la proyección, cuando se apagan las luces del salón de actos y comienzan a oírse las primeras notas y a verse las primeras imágenes y textos elaborados por los alumnos. Pero quizás lo más interesante es el debate posterior y comprobar que el texto multimodal realizado, el diaporama, está cumpliendo sus objetivos: (i) con imágenes, textos y sonidos, el grupo ha querido exponer sus conocimientos sobre un tema, este es, la posibilidad del ser humano de desplazarse libremente; (ii) se ha posicionado sobre ese tema, ya que lo ha planteado desde la declaración universal de DDHH; y (iii) ha querido compartir el tema con otros ciudadanos para escuchar más opiniones. (V. imagen 4)

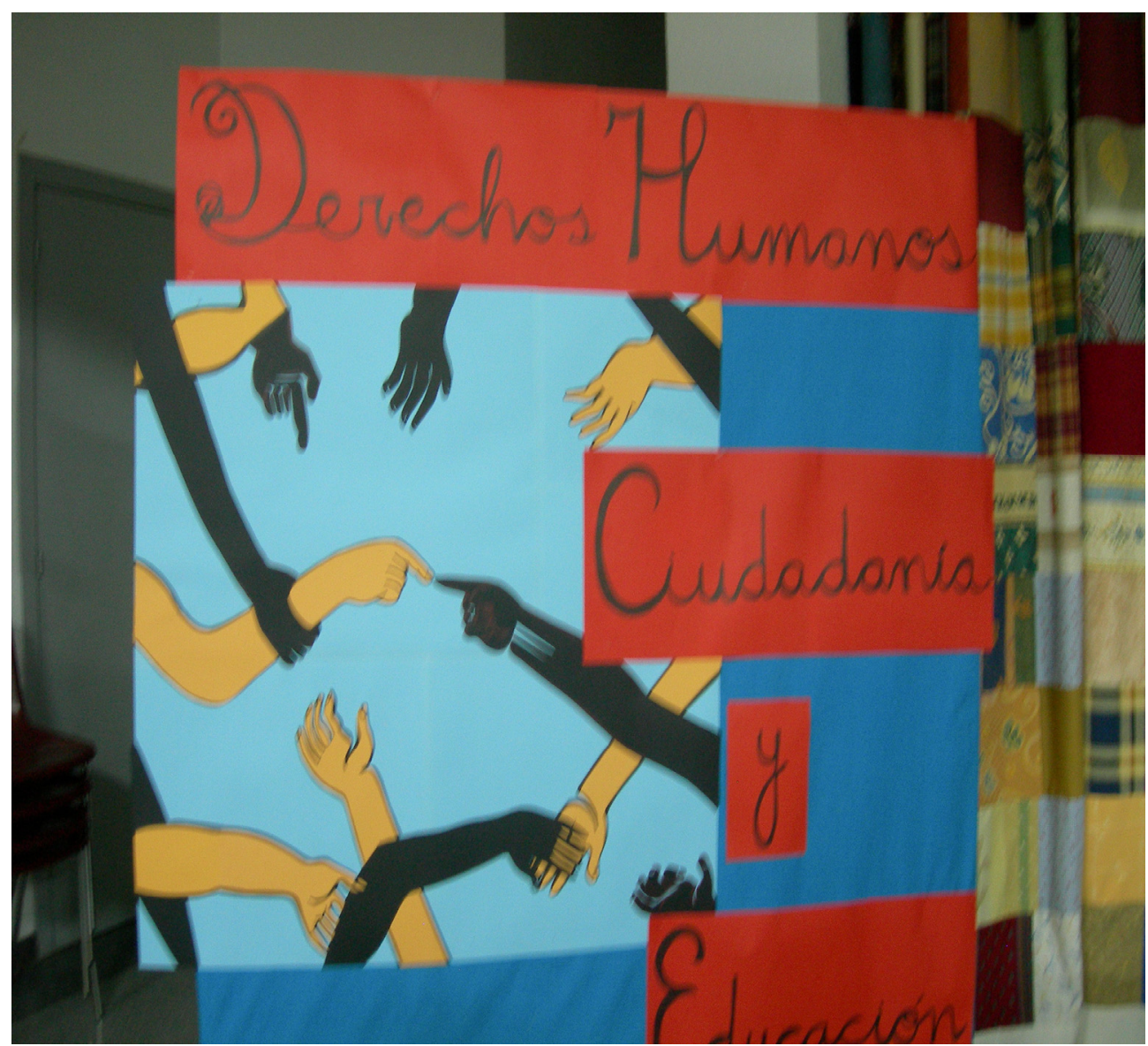

Imagen número 3 : Cartel anunciador de la sesión pública 
Cuadro número 7. Quinta fase

\section{La edición final}

5. La exposición del diaporama en público (Campos: Sociedad; Naturaleza; Comunicación; Introducción a las Nuevas Tecnologías; Matemáticas)

Previos:

El guión sobre finalidad y tipo de texto

El guión del diaporama final
. Presentación del diaporama en grupo

. Presentación del diaporama en sesión abierta

. Evaluación de la tarea: . se valora la implicación personal, el producto de cada grupo, el producto final, el aprendizaje en cada área y sobre cada tema, valorando su importancia en el mundo actual

\section{Productos de esta fase:}

. Exposición del diaporama . Debate público . Evaluación del proceso y del producto

\section{A MODO DE VALORACIÓN FINAL}

Después de haber desarrollado esta secuencia durante tres cursos académicos, nos parece interesante destacar varios aspectos:

Por una parte, el trabajo por proyectos organizado conjuntamente por todos los profesores implicados en la educación secundaria de personas adultas resulta altamente eficaz para favorecer los procesos de aprendizaje en este alumnado tan diverso. La organización actual de Educación de Personas Adultas ha roto la filosofía y los objetivos propuestos por la UNESCO relativos al aprendizaje a lo largo de toda la vida. La fragmentación en áreas de conocimiento está en contra de la experiencia de vida del adulto, y en la medida en que el lenguaje es el medio de representación del pensamiento y de comunicación entre las personas, cualquier actividad que permita mejorar estas capacidades puede articular objetivos $\mathrm{y}$ contenidos del resto de áreas. 
Con todo, no podemos dejar de señalar que gran parte del éxito o del fracaso del proyecto dependen, cada curso, de la implicación del profesorado. Un profesorado que, en los niveles de educación secundaria, accede a la Educación de Personas Adultas con una representación de la educación, mayoritariamente, de carácter compensatorio que orienta hacia unas prácticas centradas en los contenidos específicos de cada área. Los nuevos masteres oficiales de formación del profesorado de educación secundaria no tienen en cuenta esta rama del sistema educativo, como tampoco la contempla de manera explícita la formación básica del profesorado de educación primaria.

Por otra parte, los objetivos de aprendizaje que se perseguían en relación con el tipo de texto expositivo multimodal, así como su exposición pública, se alcanzan siempre satisfactoriamente. Tanto para los jóvenes que llegan a los 18 años tras su paso negativo por los institutos, pero con gran experiencia en nuevas tecnologías, como los adultos con diferentes trayectorias académicas y poca alfabetización tecnológica, el lenguaje visual resulta altamente atractivo. Comparten este interés, pero comparten también la necesidad y la búsqueda de mejores formas de expresión para exponer sus ideas ante otros jóvenes y adultos. Y no lo hacen desde el sentimiento de déficit o de fracaso académico que suele llegar a estas aulas, sino desde la ilusión de un proyecto común.

En definitiva, la experiencia permite desarrollar habilidades discursivas expositivas, orales y escritas. Pero, sobre, todo, es un proyecto global de participación ciudadana que incide en todas las áreas del currículum, y que permite ser compartido con otros lectores y espectadores que pueden sentirse motivados a debatir sobre el tema propuesto, a leer un libro y, quizás, a unirse al centro de educación de personas adultas y seguir estudiando a lo largo de la vida. 


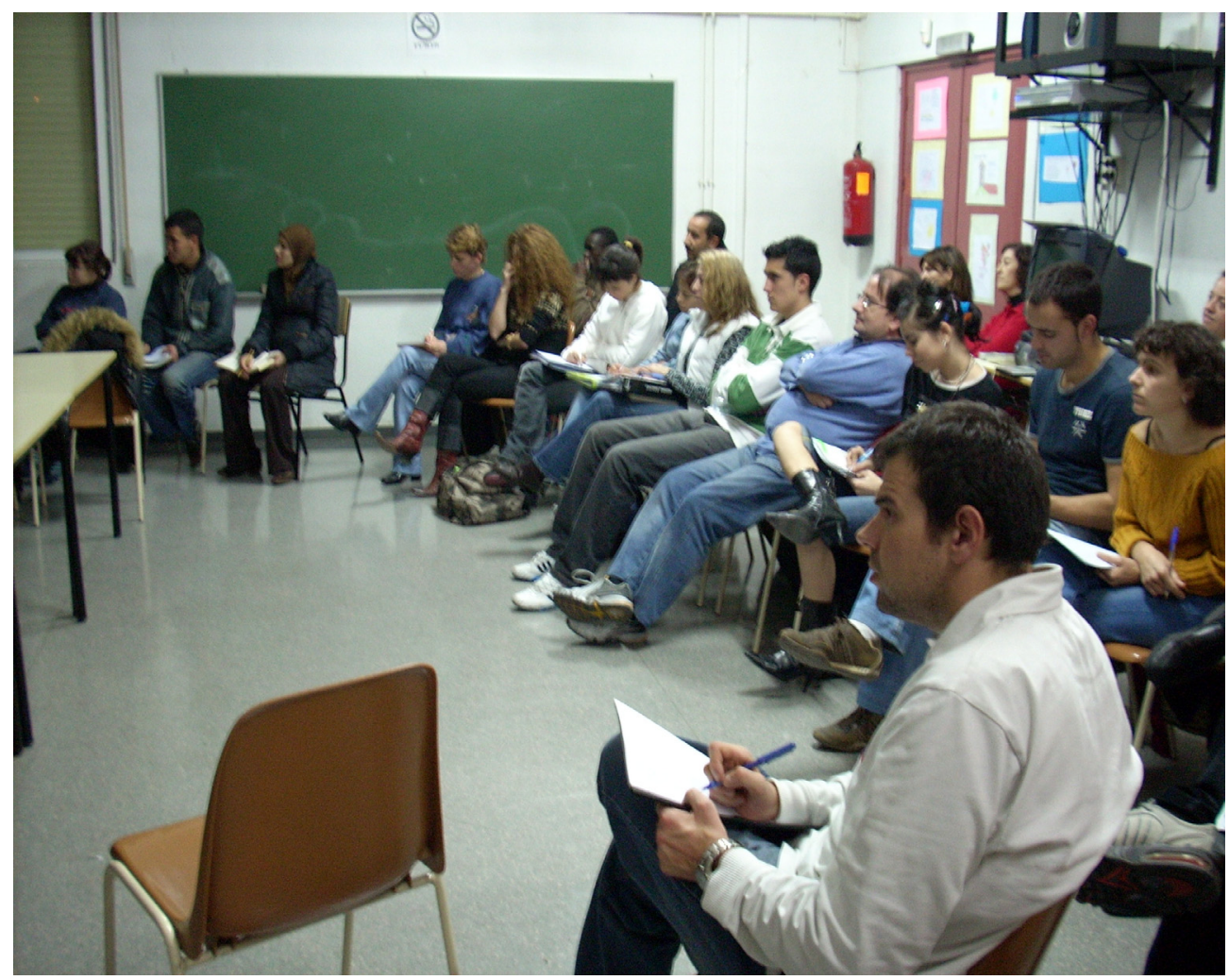

Imagen número 4: El debate tras la exposición del diaporama

\section{REFERENCIAS BIBLIOGRÁFICAS}

ALONSO, C. y D.J. GALLEGO (1991): "El aprendizaje del adulto: conozcamos cómo aprenden los adultos y los profesores al enseñar", Formación de educadores de adultos, Madrid, UNED.

AMNISTÍA INTERNACIONAL CATALUÑA: Unidades Didácticas sobre Derechos Humanos. Sugerencias para el análisis y el comentario de obras desde la perspectiva de los derechos humanos. http://www.amnistiacatalunya.org

AYUSTE, A. y otros (1994): Planteamientos de la pedagogía crítica. Comunicar y transformar, Barcelona, Graó. 
BALAGUER NADAL y otros (2002): "La formación de las personas adultas", Cuadernos de Pedagogía, 315:40-43.

BLANCO, R. (1982): La pedagogía de Paulo Freire. Ideología y método de la educación liberadora, Madrid, Zero.

BOCM. ORDEN 3888/2008, de 31 de julio, por la que se establece la organización de las enseñanzas para la obtención del título de Graduado en Educación Secundaria Obligatoria por personas adultas.

http://www.madrid.org/dat_capital/loe/pdf/Organizacion_graduadoESO.pdf

CABELLO, M.J. (2002): Educación permanente y educación social. Controversias y compromisos, Málaga, Aljibe.

CABORNERO MARTINEZ, E. (1996): "Iniciativa social. Diez años de compromiso", Panorama. Diálogos, 8, 26-29.

ClARKE, A. (1996): "Competitiveness, technological innovation and the challenge to Europe", en RAGGATT, P. y otros (eds.), The learning society. Challenges and trends, London, The Open University with Routledge, pp. 5977.

Conferencias Internacionales de la UNESCO sobre Educación de Personas Adultas (CONFINTEA) http://www.unesco.org/es/confinteavi

DIOME, FATOU (2003): Le ventre de l'Atlantique. París. Editions Anne Carrière. (Traducción española: Manuel Serrat Crespo (2004). En un lugar del Atlántico. Barcelona. Lumen).

EDWARDS, R. (1993): "The inevitable future?: post-Fordsm in work and learning" en R. EDWARDS, R. y otros (eds.) Boundaries of adult learning, London, The Open University with Routledge, pp.176-186.

EDWARDS, R. y otros (eds.) (1996): Boundaries of adult learning, London, The Open University with Routledge.

FIELD, J. (1996): "Open learning and consumer culture" en RAGGATT, P. y otros (eds.), The learning society. Challenges and trends, London, The Open University with Routledge, pp.136-149.

FLECHA, R. (1994): "Las nuevas desigualdades educativas", en AYUSTE, A. y otros; Planteamientos de la pedagogía crítica. Comunicar y transformar, Barcelona, Graó, pp.55-82.

FLECHA, R. y otros (1988): Dos siglos de educación de adultos. De las sociedades de amigos del país a los modelos actuales, Barcelona, El Roure. 
GARCIA CARRASCO, J. (2001) "La educación de personas adultas para el siglo XXI: La formación general, profesional y sociocultrual" en Actas de la III Escuela de verano: La Educación de Personas Adultas para el s.XXI, Madrid, Consejería de Educación, pp. 37-62.

GARCÍA PAREJO, I. (2011) (coord.): Escribir textos expositivos en el aula. Teoría y práctica, Barcelona, Graó.

GARCÍA PAREJO, I. (2009): “Adult migrants learning Spanish as a second language". Studies in Foreign Language Education, 1, 93-119.

GARCÍA PAREJO, I. (2004): "La enseñanza del español a adultos inmigrantes". En SÁNCHEZ LOBATO, J. y SANTOS GARGALLO, I. (eds.) Vademécum para la enseñanza del español como lengua extranjera, Madrid, SGEL, pp. 1259-1277.

GONZÁlEZ SOTO, A.P y M. GISBERT CERVERA (1990): Bases psicológicas de la educación de adultos, Zaragoza, Fondo Formación AFA.

GRUPO DIDACTEXT (2006): “Secuencia didáctica para la escritura de textos expositivos", Textos, 43, 97-106.

HART, M. (1996): Educating cheap labour", en Edwards, R y otros (eds.), Boundaries of adult learning, London, Routledge, pp.136-149.

JABONERO BLANCO, M. (1994): "La LOGSE como marco en el que se integra la educación de las personas adultas", en F. SANZ FERNANDEZ (dir.), La formación en educación de personas adultas: Madrid, UNED, II: pp.629-666.

JABONERO, M. y otros (1997): Educación de personas adultas: un modelo de futuro, Madrid, La Muralla.

JANSEN, T. y R. VAN DER VEEN (1996): "Adult education in the light of the risk society" en RAGGATT, P. y otros (eds.), The Learning Society. Challenges and Trends, London, Routledge.

LANCHO , J. (1994): "Tipología y recursos de las instituciones y entidades participantes en proyectos educativos de base territorial" en SANZ FERNANDEZ, F. (dir.), La formación en educación de personas adultas, Madrid, Universidad Nacional de Educación a Distancia, tomo 3, pp. 12251273.

LEY ORGÁNICA 2/2006, de 3 de mayo, de Educación.

http://www.boe.es/boe/dias/2006/05/04/pdfs/A17158-17207.pdf 
MORENO MARTÍNEZ, P.L. y A. VIÑAO FRAGO (1997): "La educación de adultos en España (siglos XIX y XX): Historia de una realidad cambiante y multiforme", en GARCIA CARRASCO, J. (coord.): Educación de adultos, Barcelona, Ariel, pp. 23-46.

MORENO PONS, M. (2003): "Las diapositivas como recurso didáctico: diaporamas en el aula". Revista científica de Comunicación y Edición, 21, pp. 95-100.

PALAZÓN, A. (2001): "Diaporama: percepción audiovisual". Universo fotográfico, 4 , pp. 21-43.

PÉREZ LERA, C.F (coord.) (2007): Guía de recursos educativos sobre derechos humanos. CPR de Gijón. Colección Materiales de apoyo a la acción educativa de la Consejería de educación y Ciencia del Principado de Asturias.

RAGGATT y otros (eds.) (1996): The learning society. Challenges and trends, London, The Open University with Routledge.

STOCK, A. (1996): "Lifelong learning: thirty years of educational change" en RAGGATT, P.y otros (eds.), The Learning Society. Challenges and Trends, London, Routledge, pp.10-25.

TUIJNMAN, A.C. (1996): "The expansion of adult education and training in Europe: trends and issues", en RAGGATT, P.y otros (eds.), The Learning Society. Challenges and Trends, London, Routledge, pp. 26-44. 


\section{Anexo 1}

\section{Borrador del guión técnico del diaporama}

\begin{tabular}{|c|c|c|c|c|}
\hline $\begin{array}{l}\text { Diapo } \\
\text { sitiva }\end{array}$ & $\begin{array}{c}\text { Texto } 1 \\
(\text { DDHH) }\end{array}$ & $\begin{array}{l}\text { Texto } 2 \\
\text { (novela) }\end{array}$ & Imagen posible & $\begin{array}{l}\text { Música y } \\
\text { tiempos }\end{array}$ \\
\hline $1^{\mathrm{a}}$ & $\begin{array}{l}\text { Art. 13.1.- Toda persona } \\
\text { tiene derecho a circular } \\
\text { libremente y a elegir su } \\
\text { residencia en el } \\
\text { territorio de un estado }\end{array}$ & $\begin{array}{l}\text { Título + autor }+ \\
\text { Corre, dribla, } \\
\text { regatea, chuta, cae, } \\
\text { se levanta y sigue } \\
\text { corriendo, ¡más } \\
\text { rápido! }\end{array}$ & $\begin{array}{l}\text { Fotos que } \\
\text { representen } \\
\text { personajes de la } \\
\text { novela }\end{array}$ & $\begin{array}{l}\text { Buscar } \\
\text { música } \\
\text { senegalesa } \\
\text { Valorar } \\
\text { tiempo que } \\
\text { tarda en } \\
\text { leerse cada } \\
\text { texto }\end{array}$ \\
\hline $2^{a}$ & $\begin{array}{l}\text { Art. 25.1.- Toda persona } \\
\text { tiene derecho a un nivel } \\
\text { adecuado que le asegure, } \\
\text { así como a su familia, la } \\
\text { salud y el bienestar, y en } \\
\text { especial la alimentación, } \\
\text { el vestido, la vivienda, } \\
\text { la asistencia médica y } \\
\text { los servicios sociales } \\
\text { necesarios }\end{array}$ & $\begin{array}{l}\text { Moussa estaba } \\
\text { harto de } \\
\text { contemplar la } \\
\text { miseria de los } \\
\text { suyos }\end{array}$ & $\begin{array}{l}\text { Dibujos sobre } \\
\text { su salida del } \\
\text { país }\end{array}$ & \\
\hline $3^{\mathrm{a}}$ & $\begin{array}{l}\text { Art. 1.- Todos los seres } \\
\text { humanos nacen libres e } \\
\text { iguales en dignidad y } \\
\text { derechos y, dotados } \\
\text { como están de razón y } \\
\text { conciencia, deben } \\
\text { comportarse } \\
\text { fraternalmente los unos } \\
\text { con los otros. }\end{array}$ & $\begin{array}{l}\text { Solo encontró } \\
\text { sórdidos cálculos y } \\
\text { desprecio. } \\
\text {-¿Puedo jugar? } \\
\text {-No. No } \\
\text { puedes "negrata" } \\
\text {-¡Pasa! No le } \\
\text { hagas caso }\end{array}$ & \multicolumn{2}{|c|}{ Dibujo del partido de fútbol } \\
\hline $4^{a}$ & $\begin{array}{l}\text { Art.23.1.- Toda persona } \\
\text { tiene derecho al trabajo }\end{array}$ & $\begin{array}{l}\text { No olvides que no } \\
\text { tienes papeles, } \\
\text { debes trabajar, } \\
\text { ahorrar y volver al } \\
\text { país. }\end{array}$ & \multicolumn{2}{|c|}{ Alguna foto de inmigrantes } \\
\hline $5^{a}$ & $\begin{array}{l}\text { Art.4.- Nadie estará } \\
\text { sometido a la esclavitud } \\
\text { ni a servidumbre; la } \\
\text { esclavitud y la trata de } \\
\text { esclavos están } \\
\text { prohibidas en todas sus } \\
\text { formas }\end{array}$ & $\begin{array}{l}\text { Aunque se } \\
\text { divirtiera con el } \\
\text { cálculo, } \\
\text { imaginando ser el } \\
\text { centro de } \\
\text { semejante } \\
\text { transacción, ese }\end{array}$ & \multicolumn{2}{|c|}{$\begin{array}{l}\text { Intentar hacer un montaje con } \\
\text { fondo de niños y superpuesto el } \\
\text { fútbol. }\end{array}$} \\
\hline
\end{tabular}




\begin{tabular}{|c|c|c|c|}
\hline & & $\begin{array}{l}\text { procedimiento } \\
\text { esclavista no le } \\
\text { gustaba en } \\
\text { absoluto. Pero no } \\
\text { tenía elección, } \\
\text { ahora formaba } \\
\text { parte del ganado } \\
\text { deportivo que } \\
\text { debía evaluarse. } \\
\end{array}$ & \\
\hline $6^{\mathrm{a}}$ & $\begin{array}{l}\text { Toda persona tiene } \\
\text { todos los derechos y } \\
\text { libertades proclamados } \\
\text { en esta declaración sin } \\
\text { distinción alguna de } \\
\text { raza, color, sexo, } \\
\text { idioma, religión, opinión } \\
\text { política o de cualquier } \\
\text { otra condición, índole, } \\
\text { origen nacional o social, } \\
\text { o posición económica, } \\
\text { nacimiento o cualquier } \\
\text { otra condición. }\end{array}$ & $\begin{array}{l}\text { Las palabras tejían } \\
\text { así, con la } \\
\text { minuciosidad de } \\
\text { arácnido, la línea } \\
\text { necesaria para el } \\
\text { encadenamiento y } \\
\text { el fluir de las ideas. }\end{array}$ & $\begin{array}{l}\text { Una pintura con una araña } \\
\text { capturada }\end{array}$ \\
\hline $7^{\mathrm{a}}$ & $\begin{array}{l}\text { Art. 13.1.- Toda persona } \\
\text { tiene derecho a circular } \\
\text { libremente y a elegir su } \\
\text { residencia en el } \\
\text { territorio de un estado. } \\
\text { 2.- Toda persona tiene } \\
\text { derecho a salir de } \\
\text { cualquier país, incluso } \\
\text { del propio y a regresar a } \\
\text { su país. }\end{array}$ & $\begin{array}{l}\text { Una invitación a } \\
\text { abandonar Francia } \\
\text { en setenta y dos } \\
\text { horas. La explosión } \\
\text { de la verdad le } \\
\text { cubrió de cenizas }\end{array}$ & Fotos de inmigrantes en la playa \\
\hline $8^{a}$ & $\begin{array}{l}\text { Art.2.- Toda persona } \\
\text { tiene los derechos y } \\
\text { libertades proclamadas } \\
\text { en esta declaración sin } \\
\text { distinción alguna de } \\
\text { raza, color, sexo,... }\end{array}$ & $\begin{array}{l}\text { N'Detare, su } \\
\text { maestro, aconseja a } \\
\text { los jóvenes } \\
\text { futbolistas: } \\
\text { - Francia no es lo } \\
\text { que parece. No os } \\
\text { dejéis atrapar por } \\
\text { las redes de la } \\
\text { emigración. }\end{array}$ & $\begin{array}{l}\text { Intentar comparar con dibujos la } \\
\text { situación de futbolistas famosos } \\
\text { y la del inmigrante }\end{array}$ \\
\hline
\end{tabular}




\section{Anexo 2}

Montaje audiovisual definitivo realizado por los alumnos de $2^{\circ}$ de ESPA

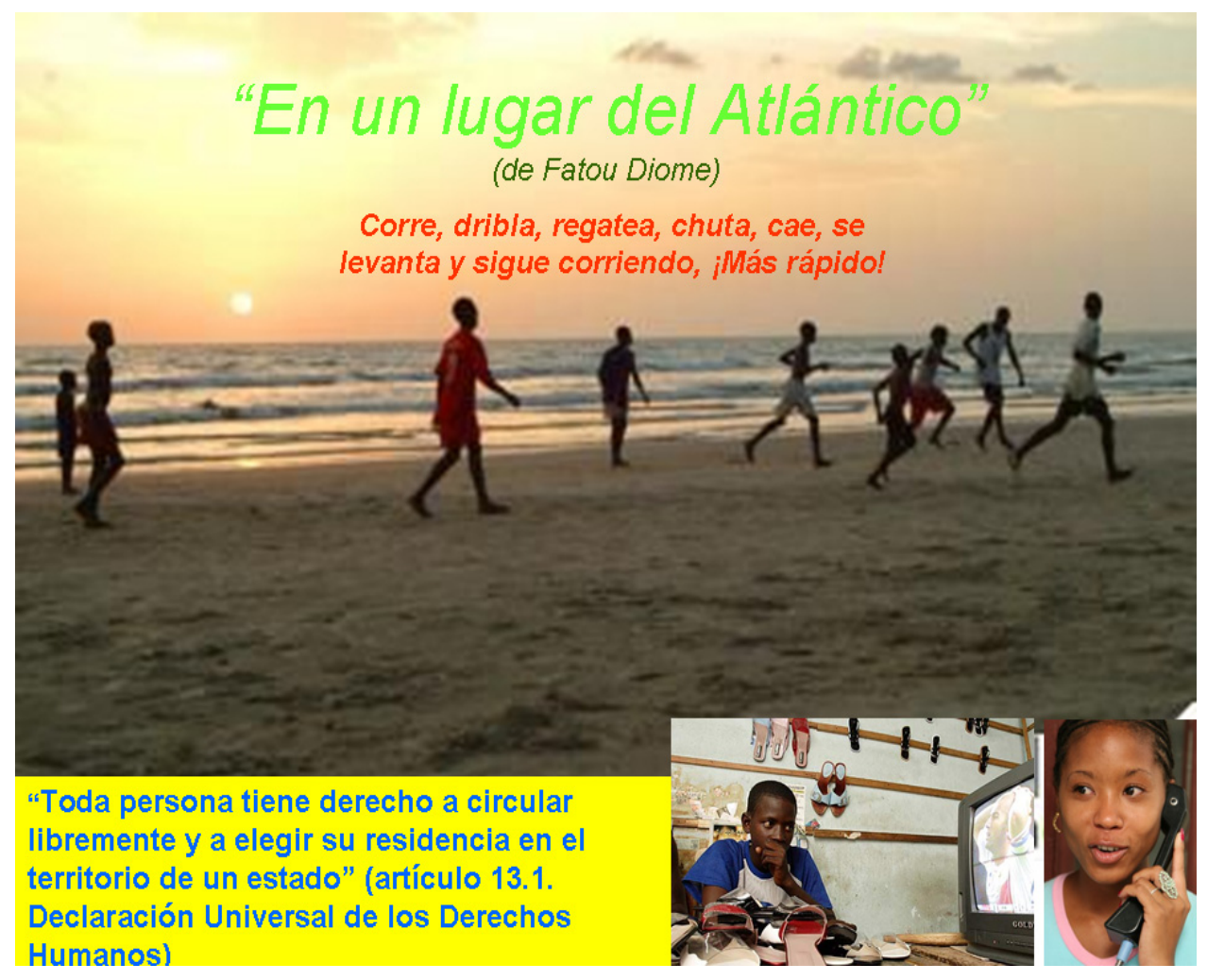




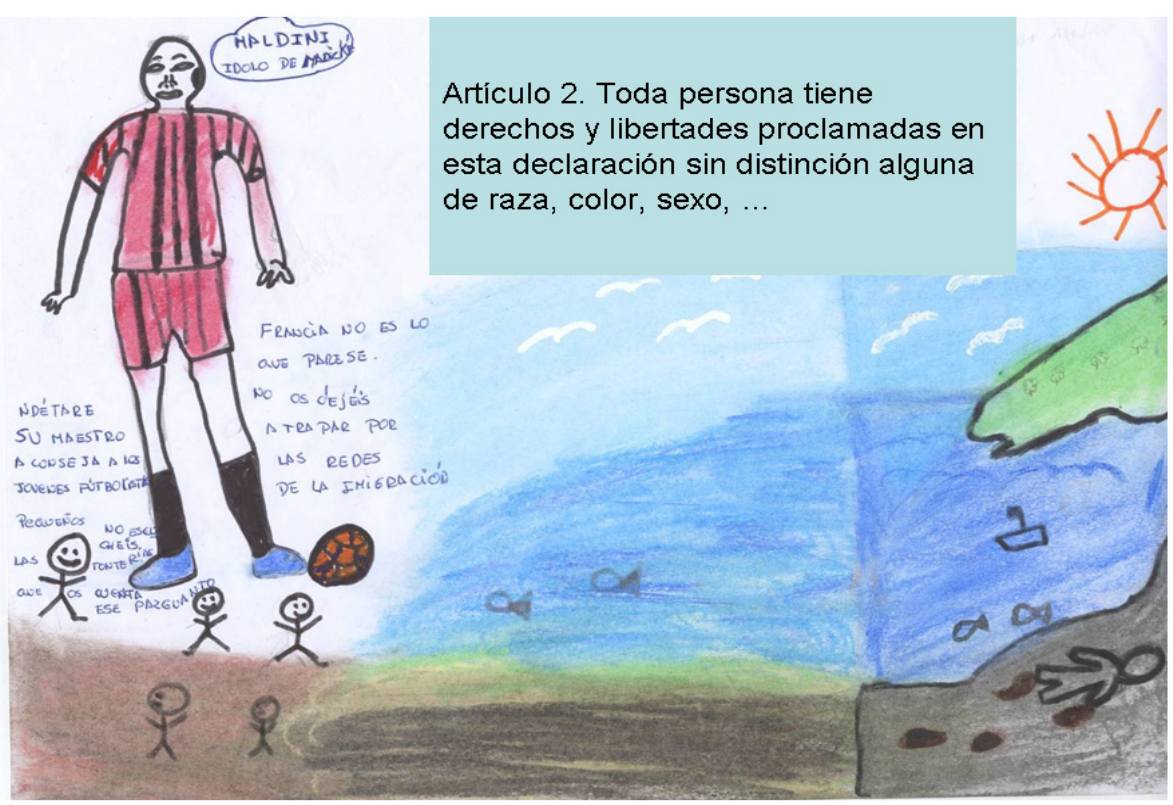

Art.25.1. Toda persona tiene derecho a un nivel adecuado que le gure, asi como a su fawilia, la saludy el bienestar, y en espacial la alimentación, el vertido, la vivienda, la asistencia médica y los Servicios sociales necesarios.

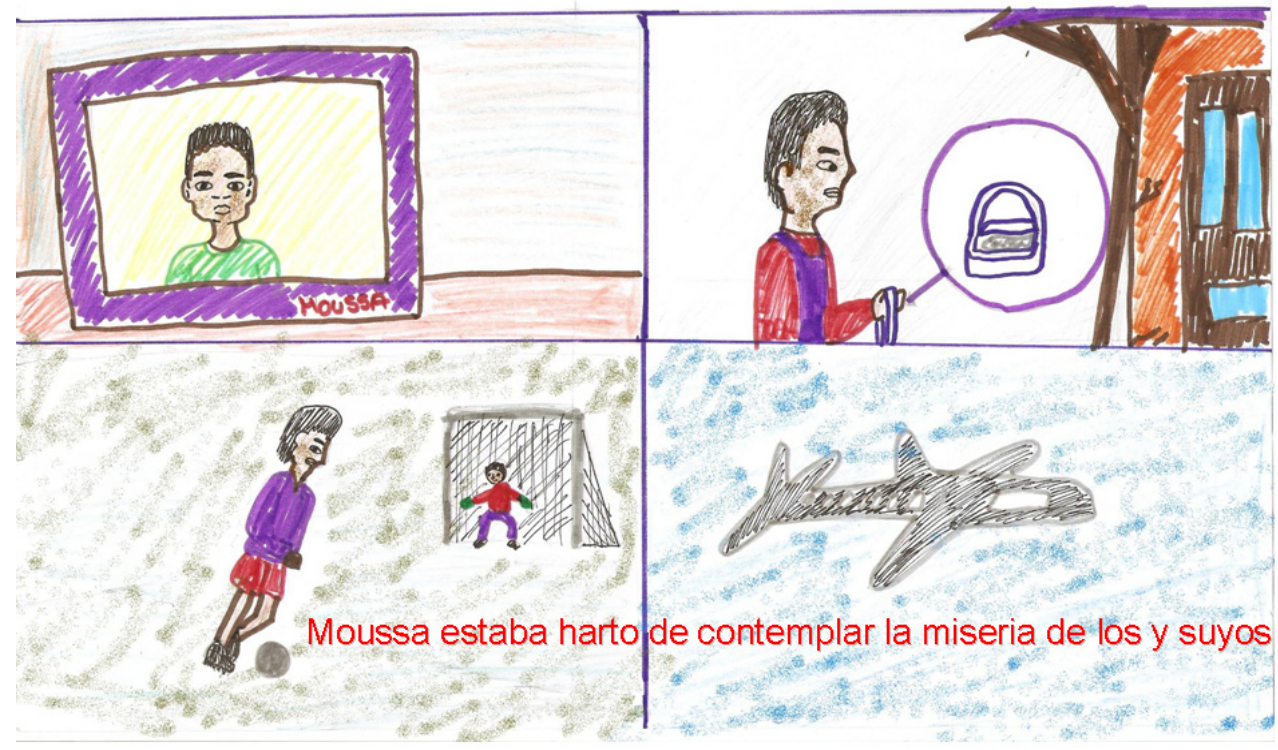




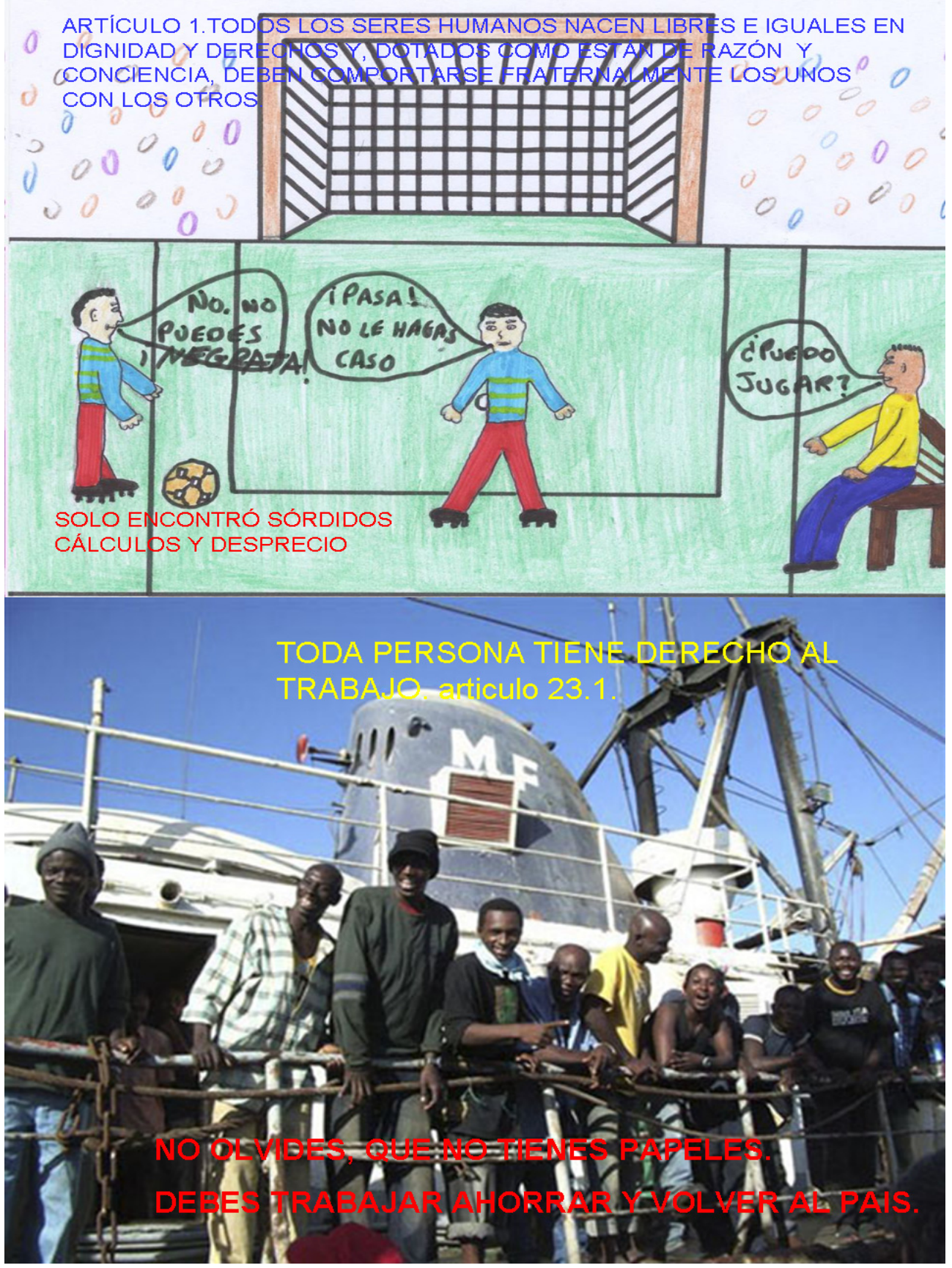




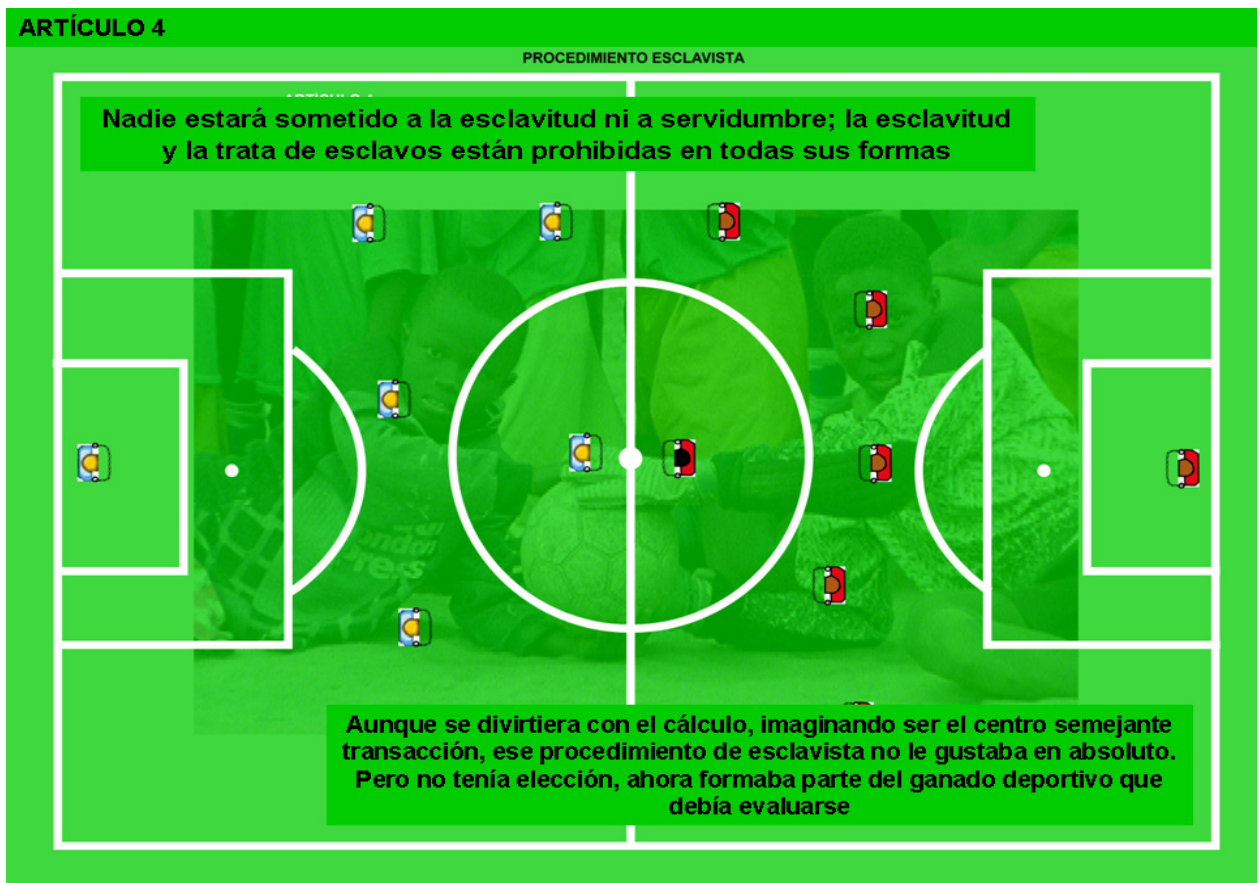

Toda persona tiene todos los derechos y libertades proclamados en esta declaración, sin distinción de alguna raza, color, sexo, idioma, religión, opinión política o de cualquier otra condición, índole, origen nacional o social, o posición económica, nacimiento, o cualquier otra condición.

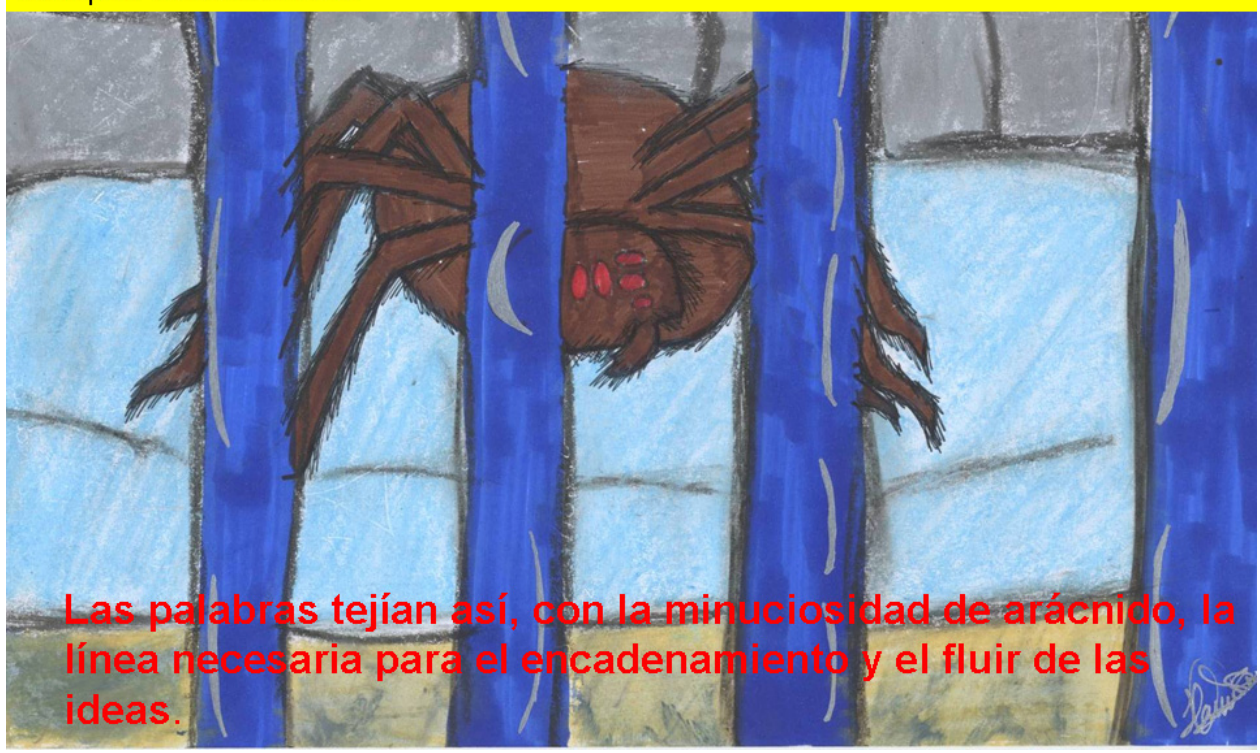




\begin{tabular}{|l|}
\hline Articulo 13. \\
1.Toda \\
persona tiene \\
derecho a \\
circular \\
libremente y a \\
elegir su \\
residencia en \\
el territorio de \\
un estado. \\
2.Toda \\
persona tiene \\
derecho a salir \\
de cualquier \\
país, incluso \\
del propio, y a \\
regresar a su \\
país.
\end{tabular}
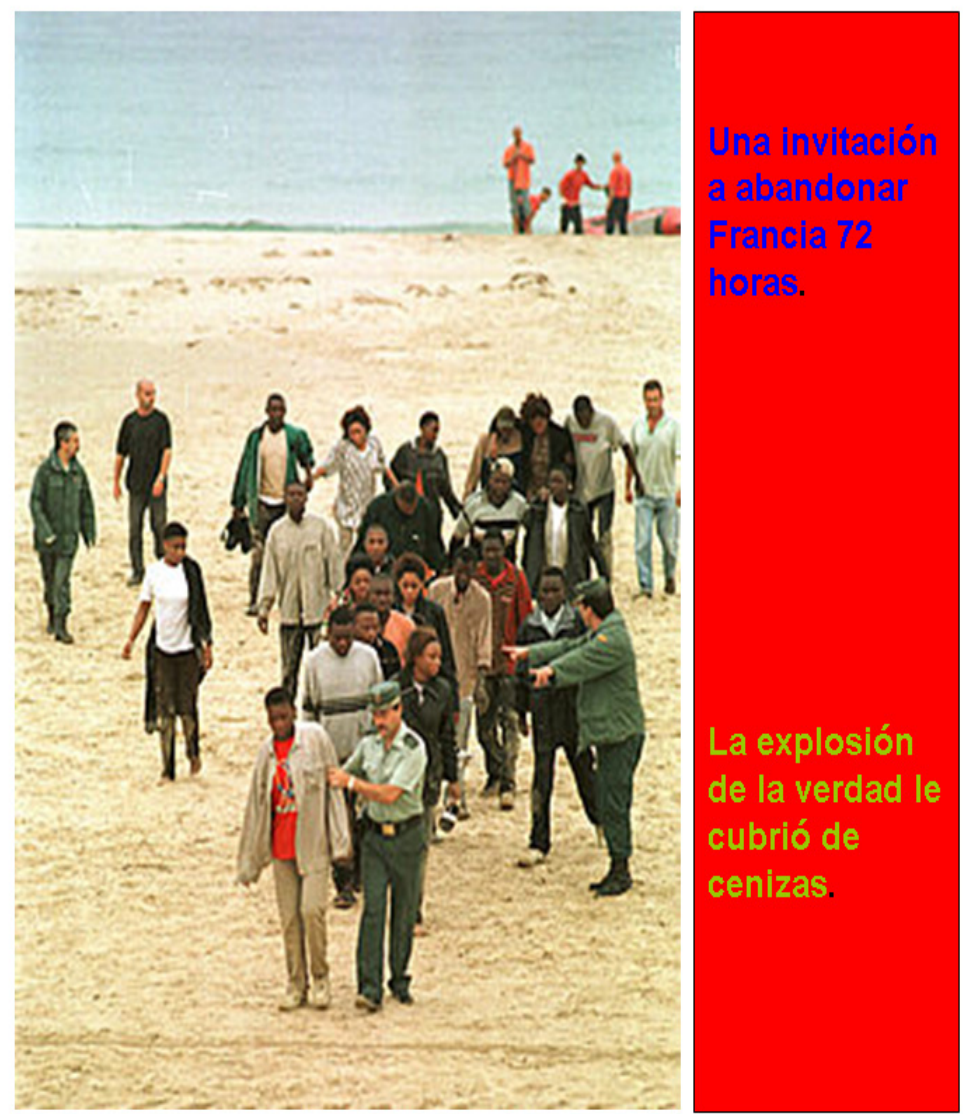